\title{
Studi Pengaruh Arcing Terhadap Karakteristik Dielektrik Minyak Sawit
}

\author{
Abdul Rajab \\ Jurusan Teknik Elektro, Fakultas Teknik, Universitas Andalas \\ e-mail: abdul_rajab@ft.unand.ac.id
}

\begin{abstract}
Abstrak - Makalah ini membahas karakteristik dielektrik minyak sawit jenis RBDPO Olein pasca gangguan listrik berupa arcing. Arcing dibangkitkan menggunakan elektroda jarum-plat melalui penerapan tegangan AC $50 \mathrm{~Hz}, 25 \mathrm{kVrms}$, dalam empat macam sampel dengan durasi yang bervariasi dari 5, 10, 15 hingga 20 menit. Karakteristik dielektrik berupa tegangan tembus, faktor disipasi dan konstanta dielektrik masingmasing sampel kemudian diuji. Sebagai pembanding, pengujian juga dilakukan terhadap minyak mineral dan minyak silikon dengan dengan kondisi dan perlakuan yang sama. Hasil observasi menunjukkan kehadiran partikel-partikel hitam menyerupai arang dalam minyak, yang konsentrasinya meningkat dengan bertambahnya durasi arcing. Konsentrasi paling tinggi ditemukan dalam minyak sawit dan paling sedikit dalam minyak silikon. Tegangan tembus minyak berkurang seiring dengan peningkatan konsentrasi partikel dalam minyak. Penurunan tegangan tembus paling besar dialami oleh minyak sawit, sedangkan tegangan tembus minyak silikon nyaris tidak berubah. Menariknya, peningkatan faktor disipasi terbesar dialami oleh minyak mineral, lalu diikuti oleh minyak silikon. Sedangkan konstanta dielektrik ketiga minyak tidak terpengaruh oleh kehadiran partikel hasil degradasi minyak.
\end{abstract}

Kata Kunci : Arcing, faktor disipasi, konstanta dielektrik, minyak sawit dan tegangan tembus

\begin{abstract}
This paper discusses the dielectric properties of palm oil due to the arcing. Arcing was generated by applying a $50 \mathrm{~Hz}$ AC voltage at $25 \mathrm{kV}$ level on the needle-plane electrode pair immersed in four type of samples which are different in arcing application durations (5, 10, 15 and 20 minutes). The dielectric properties like breakdown voltage, dissipation factor and dielectric constant of each sample were then tested. The test on mineral oil and silicone oils were also conducted under the same condition for comparison. Observation shows the presence of particles assembling carbon in the tested oils, whose concentration increased with the increase of arcing duration. The highest concentration was observed in palm oil, while the lowest one was in silicon oil. The breakdown voltage of the tested oils decreased with the increase of particle concentration, with the largest decrease was found in palm oil. Meanwhile, the breakdown voltage of silicon oil relatively unchanged. Dissipation factor of all tested oils was also found to increase with the increase of arcing duration, with the largest and the lowest changes were exhibited by mineral oil and palm oil, respectively. The dielectric constant of all tested oils remains constant during the period of arcing.
\end{abstract}

Keywords : Arcing, breakdown voltage, dissipation factor, dielectric constant, and palm oil

\section{Pendahuluan}

Penggunaan minyak sebagai isolasi dan sebagai media pendingin dalam transformator telah berlangsung sejak abad ke 19. Penggunaan minyak isolasi ini terbukti membuat transformator menjadi lebih efesien dibandingkan dengan transformator jenis kering. Jenis minyak yang paling banyak digunakan adalah minyak mineral yang diekstrak dari minyak bumi [1]. Namun demikian, dengan tingkat dan laju biodegradasi yang rendah, minyak mineral dipandang menimbulkan pencemaran lingkungan jika terjadi kebocoran serius dan/atau jika minyak dibuang [2].

Penggunaan minyak nabati sebagai minyak isolasi transformator menjadi topik hangat di kalangan peneliti dan praktisi dalam tiga dekade terakhir. Alasan utamanya adalah bahwa minyak nabati umumnya mudah terbiodegradasi, tidak beracun dan punya resiko kebakaran rendah karena titik bakarnya yang tinggi. Disamping itu, kekurangan sumber daya tidak perlu dikhawatirkan karena minyak nabati diperoleh dari tumbuh tumbuhan sehingga ketersediaannya bisa dipertahankan melalui penanaman $[3,4]$.

Secara umum material isolasi akan mengalami penuaan seiring dengan berjalannya waktu pakai. Beberapa faktor dianggap bisa mempercepat proses penuaan tersebut, diantaranya gangguan termal (thermal stress), gangguan listrik (electrical stress), reaksi kimia (chemical 
reaction) dan gangguan mekanis (mechanical stress). Gangguan termal timbul dalam bentuk panas. Gangguan listrik berupa peluahan sebagian, pemohonan atau treeing (dalam kasus padat) dan pada tingkat akut berupa arcing. Sedangkan gangguan mekanis berupa vibrasi yang dihasilkan dalam inti transformator [5]. Semua macam tekanan di atas berpotensi mengurai struktur molekul material isolasi yang bisa berujung pada situasi dimana material tidak lagi mampu mengemban fungsinya sebagai isolasi.

Sebagai salah satu jenis minyak yang diusulkan sebagai minyak isolasi alternatif, evaluasi karakteristik dielektrik minyak sawit akibat berbagai jenis gangguan (stresses) penting untuk dilakukan. Makalah ini membahas pengaruh gangguan listrik berupa arcing terhadap karakteristik dielektrik minyak sawit dan perbandingannya dengan minyak mineral dan minyak silikon.

\section{Metoda}

Metode penelitian meliputi penyiapan sampel, perlakuan (treatment) berupa pemberian tekanan listrik (arcing) dan pengujian-pengujian yang meliputi tegangan tembus, faktor disipasi dan konstanta dielektrik.

\subsection{Sampel}

Sampel yang digunakan dalam penelitian ini adalah minyak sawit jenis RBDPO olein. RBDPO merupakan singkatan dari Refined, Bleached and Deodorized Palm Oil. Sedangkan istilah olein mengacu pada fraksi cair dari RBDPO yang dihasilkan dari proses fraksinasi.

\subsection{Perlakuan dengan Arcing}

Arcing dibangkitkan dalam sampel setiap minyak menggunakan tegangan $\mathrm{AC} 50 \mathrm{~Hz}, 25$ kVrms selama 5, 10, 15 dan 20 menit. Untuk setiap durasi pemberian arcing, sampel minyak sebanyak sekitar $500 \mathrm{ml}$ ditempatkan dalam sebuah gelas beaker $1000 \mathrm{ml}$ berisi pasangan elektroda dengan konfigurasi jarum-plat berjarak $2 \mathrm{~mm}$. Rangkaian skematik pembangkitan arcing dalam sampel minyak ditunjukkan pada Gambar 1. Untuk mendapatkan efek arcing yang lebih besar digunakan tiga buah elektroda jarum yang dipasang secara paralel, sebagaimana ditunjukkan dalam Gambar 2.

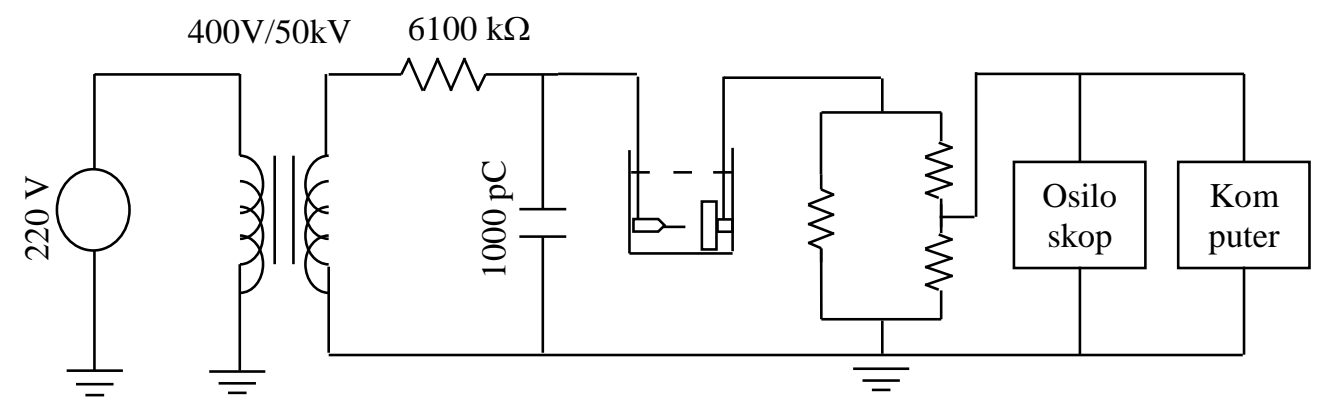

Gambar 1. Rangkaian skematik pembangkitan arcing dalam sampel minyak; $\mathrm{R}_{1}, \mathrm{R}_{2}$ dan $\mathrm{R}_{3}$ masingmasing bernilai 100, 470 dan $10 \mathrm{Ohm}$

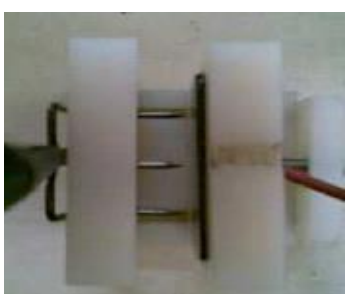

(a)

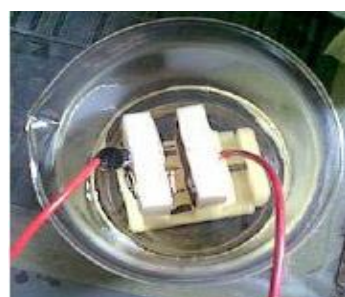

(b)
Gambar 2. Pasangan elektroda untuk membangkitkan arcing; (a) Konfigurasi elektroda, (b) Pasangan elektroda dalam gelas beaker.

\subsection{Pengujian Tegangan Tembus}

Pengujian tegangan tembus minyak dilakukan dengan mengacu pada standar pengujian IEC-156 (1995), dengan modifikasi pada jarak elektroda. Jarak elektroda $1.05 \mathrm{~mm}$ digunakan sebagai pengganti dari jarak standar 2,5 mm, untuk mengantisipasi kemungkinan adanya sampel dengan tegangan tembus lebih dari kapasitas maksimum alat, $60 \mathrm{kV}$. Penjelasan tentang prosedur pengujian ini, dengan mengabaikan faktor temperatur, tersedia dalam [6]. 


\subsection{Pengujian Faktor Disipasi dan Konstanta Dielektrik}

Konstanta dielektrik dan faktor disipasi dielektrik minyak diuji berdasarkan standar pengujian IEC-247 (2004). Penjelasan tentang peralatan dan prosedur pengujian ini bisa ditemukan dalam [7].

\section{Hasil dan Pembahasan}

\subsection{Tegangan Tembus}

Pengukuran tegangan tembus terhadap setiap sampel dilakukan sebanyak 6 kali dan nilai ratarata ke enam hasil pengukuran ditunjukkan dalam Gambar 3.

Dari Gambar 3 terlihat bahwa minyak sawit dan minyak mineral mengalami perubahan tegangan tembus cukup signifikan akibat arcing. Perubahan ini disebabkan oleh kehadiran partikelpartikel pengotor hasil degradasi molekul minyak. Konsentrasi pengotor meningkat dengan bertambahnya durasi arcing. Dalam kondisi arcing hebat, menjelang tembus, kehadirannya bisa diamati dengan kemunculan partikel berwarna hitam menyerupai arang. Di bawah pengaruh medan listrik partikel akan mengalami polarisasi dan disearahkan oleh medan sebagaimana ditunjukkan dalam Gambar 4 [8]. Dengan mengasumsikan bahwa partikel-partikel kecil tersebut berbentuk bola berjari-jari r, dan konstanta dielektrik partikel $\left(\varepsilon_{\mathrm{rf}}\right)$ dianggap lebih besar dari pada konstanta dielektrik minyak $\left(\varepsilon_{\mathrm{r} 0}\right)$, maka polarisasi oleh medan listrik akan menginduksikan muatan di kedua ujung partikel berdasarkan persamaan (1). Ujung yang lebih positif akan tertarik ke elektroda berpolaritas negatif. Ujung lain dari partikel akan berfungsi sebagai perpanjangan elektroda dan akan menarik partikel lain.

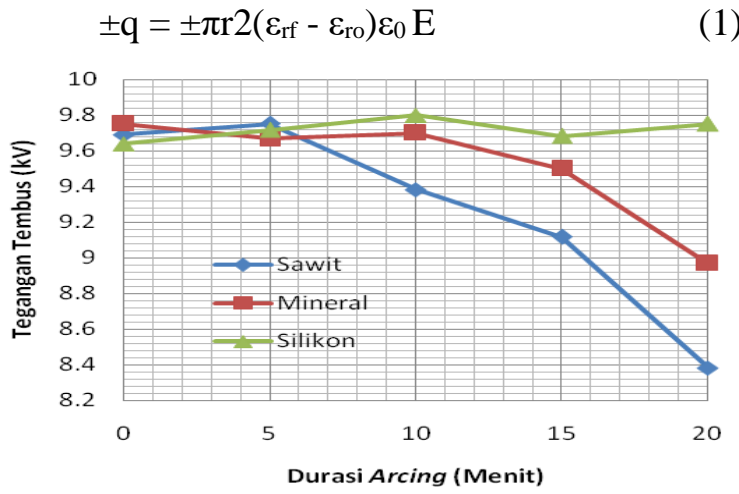

Gambar 3. Tegangan tembus minyak sawit, minyak mineral dan minyak silikon sebagai fungsi dari durasi arcing.
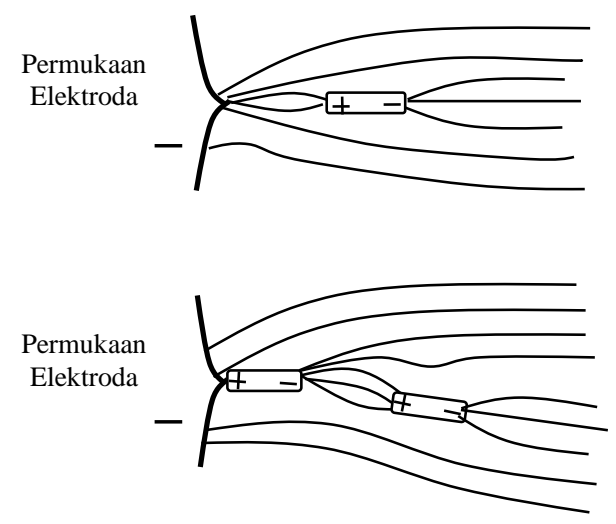

Gambar 4. Partikel-partikel mengalami polarisasi oleh medan listrik (polaritas negatif), tertarik ke arah elektroda dan bertautan satu sama lain. Saat elektroda berpolaritas positif, tanda (+) dan (-) pada partikel bertukar tempat.

Suatu gaya akan bekerja pada partikel dan mengarahkannya ke daerah yang memiliki medan listrik maksimum diantara sela elektroda. Untuk sebuah partikel kecil berbentuk bola berjari-jari r, maka gaya yang dialaminya adalah:

$$
\mathrm{F}=\mathrm{r}^{3} \varepsilon_{\mathrm{o}} \mathrm{E} \operatorname{grad} \mathrm{E}
$$

Oleh karena partikel-pertikel bergerak dalam minyak, maka gaya gesek akan bekerja berlawanan dengan gaya $\mathrm{F}$ dan dinyatakan oleh persamaan (3).

$$
\mathrm{F}_{\mathrm{s}}=6 \pi \mathrm{r \eta v}
$$

Dimana $F_{s}$ adalah gaya gesek partikel dengan minyak (N), $\eta$ adalah viskositas minyak (cSt), dan $\mathrm{v}$ adalah kecepatan partikel $(\mathrm{m} / \mathrm{s})$

Seluruh partikel yang terpengaruh medan listrik akan tertarik dan terkonsentrasi ke daerah medan listrik tinggi diantara sela elektroda. Partikel-partikel ini akan bertautan satu sama lain, dan jika konsentrasinya cukup tinggi akan membentuk jembatan yang menghubungkan kedua elektroda. Arus listrik akan mengalir melalui jembatan ini sehingga terjadilah tembus listrik (breakdown). Jika konsentrasinya rendah, maka 
partikel akan menjadi perpanjangan dari elektroda dan menghasilkan peninggian medan. Peninggian medan lokal ini bisa menyebabkan terjadinya peluahan sebagian (PD) yang bisa berkembang menjadi tembus total.

Fakta bahwa tegangan tembus minyak sawit mengalami penurunan paling besar akibat arcing dibanding minyak lain menunjukkan bahwa minyak sawit lebih rentan terhadap penguraian akibat tekanan listrik dibandingkan dengan minyak mineral dan minyak silikon. Di pihak lain, minyak silikon menunjukkan kestabilan lebih baik terhadap tekanan listrik yang tercermin dari tegangan tembusnya yang nyaris tak terpengaruh oleh pemberian arcing sampai 20 menit.

\subsection{Faktor Disipasi}

Pengukuran faktor disipasi dilakukan pada beberapa durasi arcing, dari 0 hingga 20 menit. Untuk setiap durasi, pengukuran faktor disipasi dilakukan sebanyak 2 kali dan nilai rata-rata ke dua hasil pengukuran ditunjukkan dalam Gambar 5.

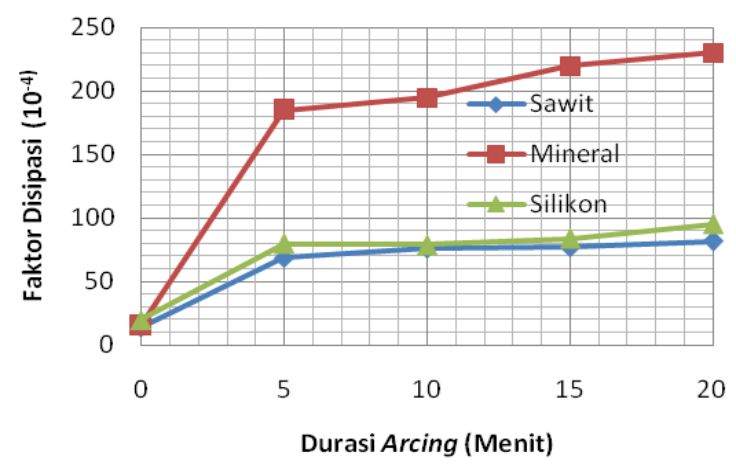

Gambar 5. Faktor disipasi minyak sawit, minyak mineral dan minyak silikon sebagai fungsi dari durasi arcing.

Gambar 5 menunjukkan bahwa ketiga jenis minyak mengalami kenaikan faktor disipasi akibat pemberian arcing. Hal ini bisa dipahami oleh karena arcing akan menyebabkan disosiasi molekul-molekul minyak, meningkatkan konsentrasi pembawa muatan (elektron atau ion), menurunkan viskositas dan meningkatkan mobilitas pembawa muatan.

Peningkatan konduktivitas listrik minyak akibat penurunan viskositasnya bisa dijelaskan melalui persamaan (4) [9].

$$
\sigma=\frac{2 Z}{\alpha<R>\eta}
$$

Dimana $\sigma$ adalah konduktivitas listrik, $\mathrm{z}$ adalah valensi ionik, umumnya diset bernilai $1, \alpha$ adalah konstanta bernilai $4 \pi,\langle\mathrm{R}\rangle$ adalah ukuran molekul bermuatan dan $\eta$ adalah viskositas.

Jumlah molekul terurai tentu saja sebanding dengan energi ( $\left.\mathrm{W}_{\text {arc }}\right)$ yang diberikan kepada molekul minyak. Dengan demikian, $\mathrm{n}$ akan meningkat dengan kenaikan durasi arcing, oleh karena energi arcing sebanding dengan durasinya berdasarkan persamaan (5).

$$
\mathrm{W}_{\mathrm{arc}}=\mathrm{V}_{\mathrm{arc}} \mathrm{I}_{\mathrm{arc}} \mathrm{t}
$$

Dimana $\mathrm{W}_{\text {arc }}$ adalah energi arcing, $\mathrm{V}_{\text {arc }}$ adalah tegangan arcing, $\mathrm{I}_{\text {arc }}$ adalah arus arcing, dan $\mathrm{t}$ adalah durasi arcing.

Fakta eksperimental yang menunjukkan bahwa faktor disipasi minyak sawit lebih rendah dibandingkan dengan minyak mineral dan sebanding dengan minyak silikon, tampak sedikit anomali, terutama jika diasumsikan bahwa minyak sawit mengalami tingkat disosiasi paling tinggi dan ditandai dengan penurunan tegangan tembus paling besar. Hasil yang terlihat seperti anomali ini bisa dijelaskan oleh keberadaan molekul air.

Pemberian arcing, meski berenergi tinggi namun berlangsung dalam durasi singkat, tidak menyebabkan pengurangan kandungan air dalam minyak, baik minyak sawit, minyak mineral maupun minyak silikon. Dalam minyak sawit, dengan tingkat kepolaran tinggi, air akan membentuk ikatan dengan bagian polar dari molekul minyak sawit, sehingga membentuk semacam perekat diantara dua molekul minyak sawit. Perekat yang terbentuk oleh molekul air ini akan menghambat pergerakan pembawa muatan dan memperkecil mobilitasnya [10]. Sementara konduktivitas listrik merupakan perkalian dari konsentrasi dengan mobilitas pembawa muatan berdasarkan persamaan $(6)[8,11]$.

$$
\sigma=n e\left(\mu_{+}+\mu_{-}\right)
$$

Dimana $\sigma$ adalah konduktivitas listrik, e adalah muatan elektron, $\mu$ adalah mobilitas ion (subscript + and - menunjukkan ion positif dan ion negatif) dan $\mathrm{n}$ adalah jumlah molekul yang terurai per satuan volume.

Dengan demikian bisa dipahami bahwa faktor disipasi minyak sawit lebih rendah dibandingkan dengan minyak mineral. Minyak silikon juga akan 
mengalami hal yang sama dengan minyak sawit meski dalam kadar rendah oleh karena tingkat kepolaran minyak silikon lebih rendah dibandingkan dengan minyak sawit. Peranan molekul air sebagai perekat antar dua molekul ini tidak terjadi dalam minyak mineral, mengingat minyak mineral tergolong senyawa non-polar.

\subsection{Konstanta Dielektrik}

Pengujian konstanta dielektrik dilakukan pada beberapa durasi arcing, dari 0 hingga 20 menit. Untuk setiap durasi, pengujian faktor disipasi dilakukan sebanyak 2 kali dan nilai rata-rata ke dua hasil pengujian ditunjukkan dalam Gambar 6.

Gambar 6 menunjukkan bahwa ketiga jenis minyak cenderung tidak mengalami perubahan konstanta dielektrik akibat pemberian arcing sampai 20 menit. Hal ini menunjukkan bahwa pemberian arcing hingga 20 menit tidak memicu reaksi oksidasi atau hidrolisis, sebagaimana yang terjadi pada kasus penuaan termal, sehingga tidak menghasilkan senyawa baru yang polar. Jika konstanta dielektrik merepresentasikan kemudahan suatu bahan dielektrik merespon aplikasi medan terhadapnya, maka konstanta dielektrik akan dipengaruhi oleh 4 macam polarisasi: elektronik, ionik, orientasi dan muatan ruang. Polarisasi elektronik dan ionik ditentukan oleh jenis atom yang menyusun suatu senyawa, dan selama pemberian arcing hingga ke pengujian konstanta dilektrik tidak terdapat penambahan maupun pengurangan atom ke dalam minyak, sehingga efek polarisasi elektronik dan ionik bisa diabaikan. Polarisasi muatan ruang juga bisa diabaikan dalam kasus pengujian konstanta dielektrik. Pengujian konstanta dielektrik (kapasitansi sel uji) menggunakan prinsip kesetimbangan jembatan schering. Arus yang mengalir selama pengujian relatif kecil sehingga tidak memungkinkan terbentuknya muatan ruang. Dengan demikian, maka faktor satu-satunya yang memungkinkan perubahan konstanta dielektrik minyak adalah perubahan kandungan dipol yang merupakan efek dari ketidakseimbangan struktur geometri molekul. Dengan kata lain, perubahan konstanta dielektrik suatu bahan ditentukan oleh perubahan kepolaran senyawa itu sendiri.

Hasil eksperimen yang menunjukkan bahwa minyak sawit memiliki konstanta dielektrik lebih tinggi dari minyak mineral dan minyak silikon menunjukkan bahwa tingkat kepolaran minyak sawit lebih tinggi dibanding dengan minyak mineral dan minyak silikon [12].

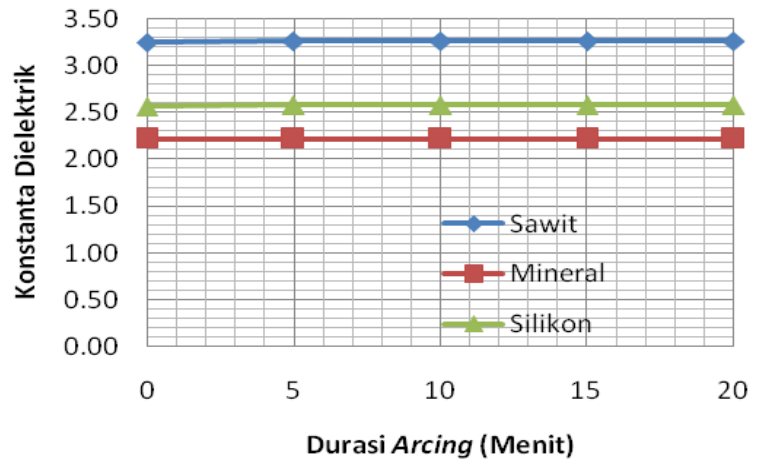

Gambar 6. Konstanta dielektrik minyak sawit, minyak mineral dan minyak silikon sebagai fungsi dari durasi arcing.

\section{Kesimpulan}

Arcing menyebabkan penurunan tegangan tembus minyak sawit dan minyak mineral akibat kehadiran zat-zat pengotor hasil degradasi minyak. Sedangkan tegangan tembus minyak silikon relatif tidak terpengaruh oleh arcing.

Faktor disipasi ketiga minyak cenderung naik dengan bertambahnya durasi arcing akibat degradasi molekul minyak. Faktor disipasi minyak sawit dan minyak silikon yang lebih rendah dibandingkan dengan minyak mineral diduga disebabkan oleh kandungan air keduanya jauh lebih besar dari minyak mineral. Molekul air yang sangat polar membentuk ikatan dengan bagian polar dari molekul minyak sawit (juga minyak silikon), menghambat mobilitas pembawa muatan sehingga faktor disipasi keduanya lebih rendah dibandingkan dengan minyak mineral.

\section{Ucapan Terima Kasih}

Ucapkan terima kasih ditujukan kepada Jurusan Teknik Elektro, Fakultas Teknik Universitas Andalas, yang sudah memberikan dukungan dan bantuan finasial sesuai dengan kontrak No. 088/UN.16.09.D/PL/2017, sehingga penelitian ini dapat dilakukan.

\section{Daftar Pustaka}

C. P. McShane, Vegetable Oil Based

Dielectric Coolant, IEEE Industrial Magazine, 34-41 (2002). 
[2] T.V. Oommen, Vegetable Oils for LiquidFilled Transformers, IEEE Electrical Insulation Magazine, 18(1), 6-11 (2002).

[3] Daniel Martin, Nick Lelekakis, Wenyu Guo and Yuriy Odarenko, Further Studies of a Vegetable-Oil-Filled Power Transformer, IEEE Electrical Insulation Magazine, 27(5), 6-13 (2011).

[4] M. Rafiq, Y. Z. Lv , Y. Zhou, K.B. Maa, W. Wang, C. R. Li and Q. Wang, Use of Vegetable Oils as Transformer oils $-a$ Review, Renewable and Sustainable Energy Reviews, 52, 308-324 (2015).

[5] Y. Wang dan J. Pan, Voltage and vibration fluctuations in power transformers, Proceedings of Acoustics (2012).

[6] Abdul Rajab, Perbandingan Tegangan Tembus Minyak Sawit dan Minyak Isolasi Jenis Mineral Pasca Penuaan Termal, Jurnal Teknika 19(2), 1-5 (2012).

[7] Abdul Rajab, Perbandingan konstanta dielektrik dan permitivitas relatif minyak sawit dengan minyak isolasi mineral pasca penuaan termal", Jurnal Nasional Teknik Elektro (2013).

[8] Khalifa M. dan Anis H., Insulating Liquids, 207-234, dalam Abdel-Salam, M., Anis. H., El-Morshedy, A. dan Radwan R. Eds, High-Voltage Engineering. Theory and Practice, ed. 2, Marcel Dekker, Inc. (2000).

[9] Abedian, B. dan Baker K. N., Temperature Effect on the Electrical
Conductivity of Dielectric Liquids, IEEE Transaction on Dielectrics and Electrical Insulation, 15, 888-892 (2008).

[10] Borsi H., Dielectric Behavior of Silicone and Ester Fluids for Use in Distribution Transformers, Journal of IEEE Transaction on Electrical Insulation, 26, 755-762 (1991).

[11] Umemura, T., Akiyama, K., Kawasaki, T. dan Kashiwazaki, T., Electrical Conduction in Synthetic Insulating Liquid', IEEE Transaction on Electrical Insulation, EI-17, 533-538 (1982).

[12] Abdul Rajab, Aminudin Sulaeman, Sudaryatno Sudirham dan Suwarno, A Comparison of Dielectric Properties of Palm Oil with Mineral and Synthetic Types Insulating Liquid under Temperature Variation, ITB Journal of Engineering Science, 43, 189-206 (2011).

\section{Biodata Penulis}

Abdul Rajab, Menyelesaikan pendidikan S1 tahun 1996 di Universitas Hasanuddin, S2 di ITB tahun 2001 dan S3 di Kyushu Institute of Technology, Japan tahun 2017. Saat ini bekerja sebagai dosen Teknik Elektro Universitas Andalas, Padang. Minat penelitian adalah minyak isolasi pada peralatan listrik tegangan tinggi, monitoring dan diagnosis kondisi sistem isolasi. 